\title{
Gamificação no ensino de leitura: 0 exemplo do jogo Veridiana
}

\author{
Mayara Rodrigues Braga (UFC)* \\ https://orcid.org/0000-0003-0132-8246 \\ Francisco Rogiellyson da Silva Andrade (UFC)** \\ https://orcid.org/0000-0002-2585-1878 \\ Dannytza Serra Gomes (UFC)*** \\ https://orcid.org/0000-0002-6204-264X
}

\section{Resumo:}

Este artigo analisa as possibilidades didáticas viabilizadas pelo jogo Veridiana (SILVA, 2017) como ferramenta pedagógica para o ensino de leitura. Embaso-nos teoricamente as considerações teóricas acerca das estratégias de gamificação em educação, tal como lançadas por Fardo (2013) e Tolomei (2017), bem com acerca das estratégias de leitura que devem ser desenvolvidas na escola, tal como pensadas por Cafieiro (2010) e Antunes (2003). A metodologia é de base qualitativa e documental. A análise permite o entendimento de que o jogo Veridiana se apresenta como ferramenta pedagógica útil para o ensino de leitura, pois promove o aprimoramento de diferentes estratégias metacognitivas de leitura, em um projeto de ensino que se ancora na dimensão interacional da linguagem.

Palavras-chave: Estratégias de gamificação. Ensino de leitura. Jogo Veridiana.

\section{Abstract:}

\section{Gamification in reading teaching: the example of the Veridiana game}

This article analyses didactic possibilities that are made possible by Veridiana game (SILVA, 2017) as a pedagogical tool for the teaching of reading. We theoretically support theoretical considerations about gamification strategies in education, based on Fardo (2013) and Tolomei (2017), as well as about the reading strategies that should be developed at school, according to Cafieiro (2010) and Antunes (2003). The methodology consists in a qualitative and documentary basis. The analysis allows the understanding that Veridiana game presents itself as a useful pedagogical tool for teaching reading, as it

\footnotetext{
* Mestranda em Linguística pelo Programa de Pós-Graduação em Linguística da Universidade Federal do Ceará. E-mail: may.braga0@gmail.com

** Mestre e Doutorando em Linguística pelo Programa de Pós-Graduação em Linguística da Universidade Federal do Ceará. E-mail: rogiellyson@yahoo.com.br

*** Pós-Doutora em Ciências da Educação pela Universidade do Porto. E-mail: dannytzasg@gmail.com
} 
promotes the improvement of different metacognitive reading strategies, in a teaching project that is anchored in the interactive dimension of language.

Keywords: Gamification strategies. Reading teaching. Veridiana game.

\section{Introdução}

Conforme preconiza a Base Nacional Comum Curricular - BNCC (2018), é objetivo do ensino de língua materna tornar os estudantes capazes de atuar de maneira ética e engajada nas diversas práticas sociais por meio da linguagem. Com esse fito, torna-se desafiador, em um contexto em que diferentes semioses verbais e não verbais configuram os textos do cotidiano, chamar a atenção dos estudantes para realizar a análise crítica desses textos a partir de metodologias tradicionalmente difundidas.

Neste artigo, entendemos que os jogos, ainda que não substituam as metodologias já difundidas para o ensino da leitura, são ferramentas que oportunizam um efetivo ensino dessa habilidade. Nossa crença decorre do fato de eles propiciarem a construção monitorada de estratégias de leitura, cumprindo, portanto, os objetivos didático -pedagógicos desse ensino.

Nessa percepção, apresentamos, neste texto, a análise do jogo Veridiana (SILVA, 2017), um Story Game, ou seja, um jogo em que os participantes são levados a narrar uma história de forma compartilhada, de maneira que o seu desenrolar só acontece ao longo da narrativa em que os jogadores participam como personagens e, assim, ao passo que desvendam, também contam a trama. Temos, como objetivo principal, analisar como o referido jogo mobiliza estratégias de leitura, a fim de formar sujeitos leitores ativamente responsivos.

Para isso, após esta introdução, discutimos algumas considerações teóricas acerca do conceito de gamificação e, em tópico posterior, das estratégias de leitura. Depois, descrevemos a metodologia que viabilizou nossa análise. Após isso, apresentamos o jogo, suas regras e analisamos de que maneira ele pode efetivar um ensino de língua baseados na fundamentação teórica que nos abaliza. Por fim, traçamos nossas considerações finais.

\section{Gamificação no ensino de língua materna}

A utilização de jogos em metodologias educacionais não é uma prática nova, visto que eles são uma construção humana que envolve fatores sócio-econômico-culturais. De acordo com Elkonin (2010), os jogos surgiram nas sociedades com o intuito de desenvolver o trabalho em grupo, bem como permitir a utilização virtual de ferramentas e artefatos que o indivíduo usa durante toda a sua vida, despertando no ser humano a sensação de recompensa ao atingir objetivos, fator crucial para a aprendizagem. Huizinga (1993) define o jogo como

uma atividade ou ocupação voluntária, exercida dentro de certos e determinados limites de tempo e espaço, segundo regras livremente consentidas, mas absolutamente obrigatórias, dotado de um fim em si mesmo, acompanhado de um sentimento de tensão e alegria (HUIZINGA, 1993, p. 33).

$\mathrm{O}$ uso de jogos, inicialmente pensados apenas para o público infanto-juvenil, recebeu um exponencial interesse dos mais variados públicos. Esse fenômeno, segundo Gee (2009), acontece em decorrência de os 
jogos serem ferramentas que engajam seus usuários, promovendo habilidades inerentes à apreensão da identidade, à promoção da interação, à apreensão de riscos, à resolução de problemas e desafios e à criação. Essas características, conforme Huizinga (1993), propiciam um processo de aprendizagem de forma contextualizada, engajando os jogadores, de forma a interagir com o meio, com a situação de interação e com os outros indivíduos, respeitando as regras do jogo e, por isso, sendo levados a agir de maneira ética.

Mattar (2018) observa esse fenômeno em áreas como computação e marketing, que aproveitaram o auge dessa temática para disseminar o processo de gamificação ${ }^{1}$ em suas esferas, trazendo estratégias gamificadas para aplicativos de assessoria esportiva, bancos, programas de milhagem e propaganda. Essa ação foi amplamente aceita e bem quista pelo público. Dado o caráter desafiador e lúdico dos games, práticas cotidianas e repetitivas, como a visita a uma padaria, tornaram-se mais instigantes com a pontuação do Foursquare ${ }^{2}$, por exemplo, e, portanto, melhor assimiladas pelos usuários, trazendo um excelente custo-benefício para o público em geral e para os desenvol- vedores de web e disseminadores de conteúdo.

Para Alves et al. (2014, p. 76), a prática de adotar características de jogos em serviços, aplicativos ou aprendizagem "se constitui na utilização da mecânica dos games em cenários non games, ou seja, fora de games, criando espaços de aprendizagem mediados pelo desafio, pelo prazer e entretenimento".

Em concordância com isso, entendemos gamificação tal como postula Fardo (2013, p. 13), para quem o conceito se refere ao "uso de elementos, estratégias e pensamentos dos games fora do contexto de um game, com a finalidade de contribuir para a resolução de algum problema". Nessa formulação, em consonância com Gee $(2009,2014)$, Prensky (2012), Kenski (2012) e Deterding et al. (2011), entende-se que o uso das estratégias gamificadas no contexto escolar configura-se como ferramenta valiosa de aprendizado.

Coadunados com isso, Fardo (2013) e Tolomei (2017) propõem uma gama de estratégias que gamificam uma atividade escolar. Expomos, a seguir, com base nesses autores, os elementos necessários para que ocorra a composição de um game em atividades escolares.

Quadro 1: Estratégias de gamificação

\begin{tabular}{|c|l|}
\hline \multicolumn{1}{|c|}{ Elementos } & \multicolumn{1}{c|}{ Descrição } \\
\hline Narrativa & História que promove a imersão do jogador \\
\hline Níveis & $\begin{array}{l}\text { Divisão do jogo em partes, geralmente com dificuldades incrementais; também } \\
\text { chamadas de fases. }\end{array}$ \\
\hline Desafio/Missões & $\begin{array}{l}\text { Objetivos que o jogador deve alcançar a partir de tarefas específicas que o usuário } \\
\text { deve realizar dentro de um sistema, sendo recompensado de alguma maneira } \\
\text { por isso (pontos e medalhas). Cria o sentimento de desafio para o usuário do } \\
\text { sistema. }\end{array}$ \\
\hline
\end{tabular}

1 Utilizamos o termo gamificação com base na grafia de Gee $(2009,2014)$.

2 Foursquare é uma rede geossocial e de microblogging que permite ao utilizador indicar onde se encontra, e procurar por contatos seus que estejam próximo desse local. 0 aspecto lúdico vem do fato de ser possível acumular distintivos relativos a lugares específicos. 


\begin{tabular}{|c|l|}
\hline Regras & Restrições ou limitações impostas pelo jogo. \\
\hline Feedback & $\begin{array}{l}\text { Resposta a uma ação do jogador, que possibilita imediatamente uma confirmação } \\
\text { ou reavaliação das escolhas e táticas. }\end{array}$ \\
\hline Competição & $\begin{array}{l}\text { Relacionamento entre jogadores ou times, que promove a busca por ser o melhor. } \\
\text { Se bem estimulada, pode promover inúmeras aprendizagens. Pode-se também } \\
\text { competir consigo mesmo numa busca por superação. }\end{array}$ \\
\hline Engajamento & O que motiva o jogador a jogar. \\
\hline Recompensa & Benefício adquirido após alguma ação ou conclusão de uma missão. \\
\hline Pontuação/ & $\begin{array}{l}\text { Forma quantificável do status do jogo. Sistema de pontos de acordo com as tarefas } \\
\text { que o usuário realiza; este é recompensado com uma quantidade determinada } \\
\text { de pontos. }\end{array}$ \\
\hline Ranking & $\begin{array}{l}\text { Uma maneira de visualizar o progresso dos outros usuários e criar um senso de } \\
\text { competição dentro do sistema. }\end{array}$ \\
\hline
\end{tabular}

Fonte: Elaborado pelo autor, com base em Fardo (2013) e Tolomei (2017).

Com relação ao desenvolvimento de competências e habilidades referentes à língua materna, todo e qualquer jogo, a partir das estratégias expostas no Quadro 1, mobiliza do jogador uma série de habilidades necessárias para a interação, o que leva o jogador a construir sentido a todo o momento a partir da construção de sentidos emergidos pelas diferentes linguagens.

Vistos sob a ótica educacional, os jogos podem ser integrados ao ensino de línguas para contribuir com os eixos concernentes à língua materna, estipulados pela BNCC (2018), a saber: produção textual, leitura, análise linguística/semiótica e oralidade. A hipótese é a de que a inserção de jogos na escola seja um fator de motivação intelectual e cognitiva, capaz de fomentar o desenvolvimento de habilidades linguísticas para a construção de letramentos, sob o amparo de atitudes éticas.

Desconstrói-se, assim, a ideia de que os jogos são tão somente utilizados como maneira de ludicizar as aulas - o que não deixa de ser verdade -, porém acredita-se que, para além disso, eles também são materiais propulsores da aprendizagem significativa no que se refere ao ensino de língua. Con- forme afirma Rojo (2012), é necessário construir metodologias de ensino de língua que retirem os sujeitos do patamar de consumidores acríticos, tornando-os analistas críticos. Tal objetivo é reiterado por órgãos como a UNESCO (2015) ao afirmar que os indivíduos, ao serem imersos em práticas de análise, tornar-se-ão criativos e críticos, cidadãos competentes e participativos, atores indispensáveis para que a sociedade da informação ou do conhecimento seja plural, inclusiva e participativa.

Daí surge o mote de nossa pesquisa, que pretende investigar como o uso de jogos no ensino de leitura propicia a construção de estratégias de leitura, viabilizando seu desenvolvimento e a consciência delas, com o fito de construir letramentos. A seguir, apresentamos algumas considerações teóricas acerca das estratégias de leitura.

\section{Estratégias de leitura}

Os estudos em Linguística Aplicada, tais como os de Kleiman (2007) e Soares (2008), apontam para o entendimento de que a leitura é uma prática social. Assim, para ler, Koch; Elias (2012) e Silva (1999) defendem que o leitor seja imerso num contexto de interação 
socialmente delimitado e real, a fim de que possa se engajar na atividade de leitura.

Entendida a leitura sob essa ótica, fazse necessário, então, que se mobilizem estratégias cognitivas e metacognitivas, a fim que o leitor efetive sua leitura e consiga formular sua compreensão. Kleiman (1997) afirma que as estratégias cognitivas dizem respeito a atividades inconscientes realizadas pelo leitor. 0 fatiamento sintático e o processamento de informações, segundo exemplifica a autora, seriam evidências dessas estratégias, uma vez que não é possível realizar uma reflexão consciente acerca disso. Obviamente, há estratégias para que isso ocorra, mas não é possível estipular regras para elas. A exemplo disso, quando o leitor se depara com um texto que apresenta muitas informações novas, é comum que ele retome a leitura de parágrafos e faça essa leitura mais pausadamente, justamente porque isso pode ser uma estratégia, mas não é possível que ele meça a quantidade de informação que recebe, já que isso se processa inconscientemente.

As estratégias metacognitivas, por seu turno, dizem respeito a atividades monitoradas e conscientes a serem realizadas pelo leitor. Nessa orientação, cada exemplar textual exige diferentes estratégias, sendo dever do ensino de língua materna fornecer subsídios teórico-práticos para que os estudantes monitorem as atividades necessárias para os diferentes gêneros de discurso, de maneira a tornar "a sua leitura uma atividade consciente, reflexiva e intencional" (KLEIMAN, 1997, p. 51). Assim, as estratégias metacognitivas de leitura se dividem, segundo Kleiman (1997), em duas macrocategorias: a seleção de objetivos de leitura e, em consequência disso, o empreendimento de uma automonitoração da compreensão, que leve o leitor a selecionar as informações de que necessita, o que demonstra que o sentido só emerge na própria interação.

Em torno disso, por exemplo, para um estudante de língua materna, torna-se diferente ler um romance de Machado de Assis, porque gosta da literatura desse autor e gostaria de fruí-la, de ler o mesmo romance para cumprir uma atividade avaliativa escolar, uma vez que a seleção de objetivos, ainda que para o mesmo texto, se redimensiona. Mas, além disso, numa conjuntura ou em outra, a partir da seleção de objetivos, é preciso, também, entender quem foi o autor do romance, em que época viveu, que traços culturais marcam a sociedade em que se engajou etc. De igual maneira, é preciso, também, conhecer o gênero por meio do qual o texto se engendra, perceber como ele desenvolve a temática, quem são os personagens, como os elementos da narrativa se constroem nesse texto, como o estilo do autor se marca no romance, que efeitos de sentido se erigem a partir das seleções vocabulares, sintáticas e metafóricas. Ainda, o leitor há de ter que mobilizar seu conhecimento de mundo, seu conhecimento linguístico, bem como analisar sua própria historicidade, os traços culturais que marcam a sociedade em que vive e o contexto de leitura em que se engaja. Todas essas ações formam um feixe complexo que se engendra no ato de ler, revelando, por isso, o emaranhado de habilidades necessárias à construção de um leitor crítico.

Percebendo isso, Kleiman (1997) propõe a necessidade de o ensino de leitura se calcar no desenvolvimento de habilidades que tornem o ato de ler significativo e praticável para os sujeitos. As primeiras habilidades, referentes a estratégias cognitivas, seriam aquelas que propõem o reconhecimento de estruturas sintáticas, complexas ou não, bem como da estrutura morfológica das palavras e da apropriação do vocabulário. 
0 ensino dessas habilidades envolveria fazer um trabalho com o texto que visasse, por um lado, desenvolver a capacidade do aluno para usar seu conhecimento gramatical implícito (morfossintático e semântico), e, por outro, a sua capacidade de identificar palavras mediante reconhecimento visual instantâneo. (KLEIMAN, 1997, p. 66).

Nessa proposta, é necessário que o ensino de leitura possa, por exemplo, fornecer o trato com textos que utilizam diferentes modalidades linguísticas, partindo de gêneros com estruturas sintáticas menos complexas até as mais complexas, justamente para que os aprendizes tenham contato com esses diferentes recursos. Além disso, é necessário, através disso, fazer o estudante inferir o sentido de palavras e expressões dentro do contexto de interação em que está imerso. A operação de reconhecimento dos itens lexicais é inconsciente, mas a ancoragem de sentidos é uma habilidade que deve ser monitorada pelo leitor.
Cafiero (2010), ao encontro desse entendimento, defende que o leitor é sujeito ativo desse processo, pois ele

não age apenas decodificando, isto é, juntando letras, sílabas, palavras, frases, porque ler é muito mais do que apenas decodificar. Ler é atribuir sentidos. E, ao compreender o texto como um todo coerente, o leitor pode ser capaz de refletir sobre ele, de criticá-lo, de saber como usá-lo em sua vida. [...] É importante que, nas aulas de leitura, o aluno faça perguntas, levante hipóteses, confronte interpretações, conte sobre o que leu e não apenas faça questionários de perguntas e respostas de localização de informação. (CAFIEIRO, 2010, p. 86).

Para realizar essa complexidade de ações ativas, é necessário, pois, explicitar ao estudante as estratégias metacognitivas que deve empreender para construir sua compreensão. Estas são atividades conscientes do leitor, que o levam a efetivar seu projeto de leitura. Em sua proposta, Cafieiro (2010) entende que essas estratégias são:

Quadro 2: Estratégias de leitura.

\begin{tabular}{|c|c|}
\hline \multicolumn{2}{|c|}{ Estratégias de leitura } \\
\hline Fixar objetivos & Contextualizar o texto \\
\hline Mobilizar conhecimentos de mundo & Fazer predições \\
\hline Localizar informações & Inferir sentido de palavras e expressões \\
\hline Identificar opiniões expressas no texto & Identificar a finalidade dos textos \\
\hline Relacionar imagem e texto & Identificar a função do uso de articuladores \\
\hline $\begin{array}{c}\text { Estabelecer relações entre partes } \\
\text { de um texto de modo a (re)construir a } \\
\text { continuidade temática }\end{array}$ & $\begin{array}{c}\text { Relacionar recursos expressivos } \\
\text { e efeitos de sentido }\end{array}$ \\
\hline $\begin{array}{c}\text { Perceber efeitos de variação linguística } \\
\text { Ler globalmente }\end{array}$
\end{tabular}

Fonte: Cafieiro (2010).

Parte-se da hipótese de que, ao desenvolver essas estratégias, os estudantes tornam-se capazes de ler os mais diferentes gêneros dis- cursivos com os quais se deparam e, em consequência disso, de compreender o texto à luz dos objetivos selecionados para sua leitura. 
Antunes (2003), admitindo a dimensão interacional da linguagem, afirma que, ao ancorar-se nessa perspectiva, há uma série de implicações pedagógicas para as quais o professor deve se atentar ao planejar aulas de leituras.

Quadro 3: Implicações pedagógicas da dimensão interacional da linguagem para o ensino da leitura.

\begin{tabular}{|c|c|}
\hline \multicolumn{2}{|c|}{ O ensino de leitura deve envolver a... } \\
\hline Leitura de textos autênticos & Leitura interativa \\
\hline Leitura em duas vias & Leitura motivada \\
\hline Leitura do todo & Leitura crítica \\
\hline Leitura da reconstrução do texto & Leitura diversificada \\
\hline Leitura por fruição & Leitura apoiada no texto \\
\hline Leitura não só das palavras expressas no texto & Leitura nunca desvinculada do sentido \\
\hline
\end{tabular}

Fonte: Antunes (2003).

$\mathrm{Na}$ dimensão dessas implicações pedagógicas, entende-se que a mediação da leitura no ensino básico deve permitir que o leitor realize um encontro interativo com o produtor do texto que lê, com a intenção de propiciar subsídios teórico-práticos para que o estudante se capacite a monitorar sua leitura e possa, assim, ser um sujeito ativo nesse processo, portanto alguém engajado na situação de interação. Como dizem Silva (1999), Cafieiro (2010) e Koch; Elias (2012), a leitura é um ato interativo de produção de sentidos, é necessário que tanto o texto quanto o leitor se transformem nesse evento, o que só é possível quando o leitor se entende como protagonista da interação.

Embasados nessas considerações teóricas, a seguir, apresentamos a metodologia que viabilizou este estudo.

\section{Metodologia}

A presente pesquisa insere-se no campo da Linguística Aplicada. Consiste em uma pesquisa documental (GIL, 2002), na qual adotamos a abordagem qualitativa (MINAYO, 2011) para a análise dos dados. Minayo (2011, p. 21) fala que "[...] a pesquisa qualitativa responde a questões muito particu- lares. Ela se preocupa [...] com um nível de realidade que não pode ser quantificado [...]", objetivando, nessa orientação, descrever, explicar e compreender a natureza dos fenômenos pelos quais o pesquisador se interessa.

Com base nisso, nossa investigação é fruto de estudos bibliográficos acerca do ensino de leitura e dos elementos de gamificação. Além disso, partimos também de estudos documentais com base na análise do jogo Veridiana e suas possibilidades de didatização para aulas de leitura. É importante destacarmos aqui a diferença entre pesquisa bibliográfica e pesquisa documental:

A pesquisa documental trilha os mesmos caminhos da pesquisa bibliográfica, não sendo fácil por vezes distingui-las. A pesquisa bibliográfica utiliza fontes constituídas por material já elaborado, constituído basicamente por livros e artigos científicos localizados em bibliotecas. A pesquisa documental recorre a fontes mais diversificadas e dispersas, sem tratamento analítico, tais como: tabelas estatísticas, jornais, revistas, relatórios, documentos oficiais, cartas, filmes, fotografias, pinturas, tapeçarias, relatórios de empresas, vídeos de programas de televisão, etc. (FONSECA, 2002, p. 32). 
Neste estudo, a principal base de análise é o jogo Veridiana. A escolha por esse jogo é decorrente de ele estar disponível na internet $^{3}$, para que sejam impressos os materiais necessários a seu uso. Por conta disso, julgamos ser importante analisar a oportunidade que um jogo como esse, que se encontra num espaço gratuito para que todo professor possa utilizá-lo, tem de auxiliar na aula de leitura. À luz dessa perspectiva metodológica, no tópico a seguir, apresentamos o jogo e também realizamos nossas considerações analíticas acerca das possibilidades didáticas que ele edifica para a aula de leitura.

\section{Apresentação e análise do jogo}

Veridiana é um jogo-livro. Ao longo desta análise, portanto, utilizamos a nomenclatura jogadores-leitores para fazer referência aos participantes, uma vez que eles não somente assumem a posição de jogadores na tentativa de cumprir as regras estabelecidas para cumprir o objetivo da competição, mas também se posicionam como leitores que desenvolverão estratégias de leitura. Só é possível jogar Veridiana se mobilizadas tais estratégias, tal como podemos perceber.

Também por ser um jogo-livro, Veridiana é importante para desmistificar algumas concepções acerca do uso de jogos em sala de aula, já que não é necessária a utilização de games virtuais, que necessitam de um aparato tecnológico mais sofisticado, pois, conforme discutem Alves et al. (2014) e Fardo (2013), utilizar a gamificação é aplicar mecânicas de games a atividades que, prioritariamente, não se realizam através de games. Assim, por estar disponível na internet gratui-

3 O jogo encontra-se disponível no link: <https:// drive.google.com/drive/u/0/folders/0Bzjv8bDBeux4MU5IbDRaTVd5bWs>. Acesso em: 10 mai. 2020. tamente, o professor pode imprimir todo o material necessário para utilizar o jogo com a turma que deseja. Nesse sentido, o jogo-livro é jogado em formato físico, salientando que as estratégias de gamificação não são sinônimo de uso de games apenas no âmbito digital, mas é a aplicação de mecânicas de design de games (MATTAR, 2018).

No jogo disponibilizado, há os seguintes materiais: o jogo-livro, que apresenta as orientações e as páginas com o desenrolar do enredo, chamado pelo autor do livro de manual de instruções; a ficha de personagem, que, conforme é orientado no manual, cada participante deve possuir uma cópia; e a ficha de centro de mesa, onde os participantes devem jogar os dados e que fornece as ações que devem ser realizadas a partir do resultado de cada dado.

Figura 1: Capa do manual de instruções do jogo Veridiana

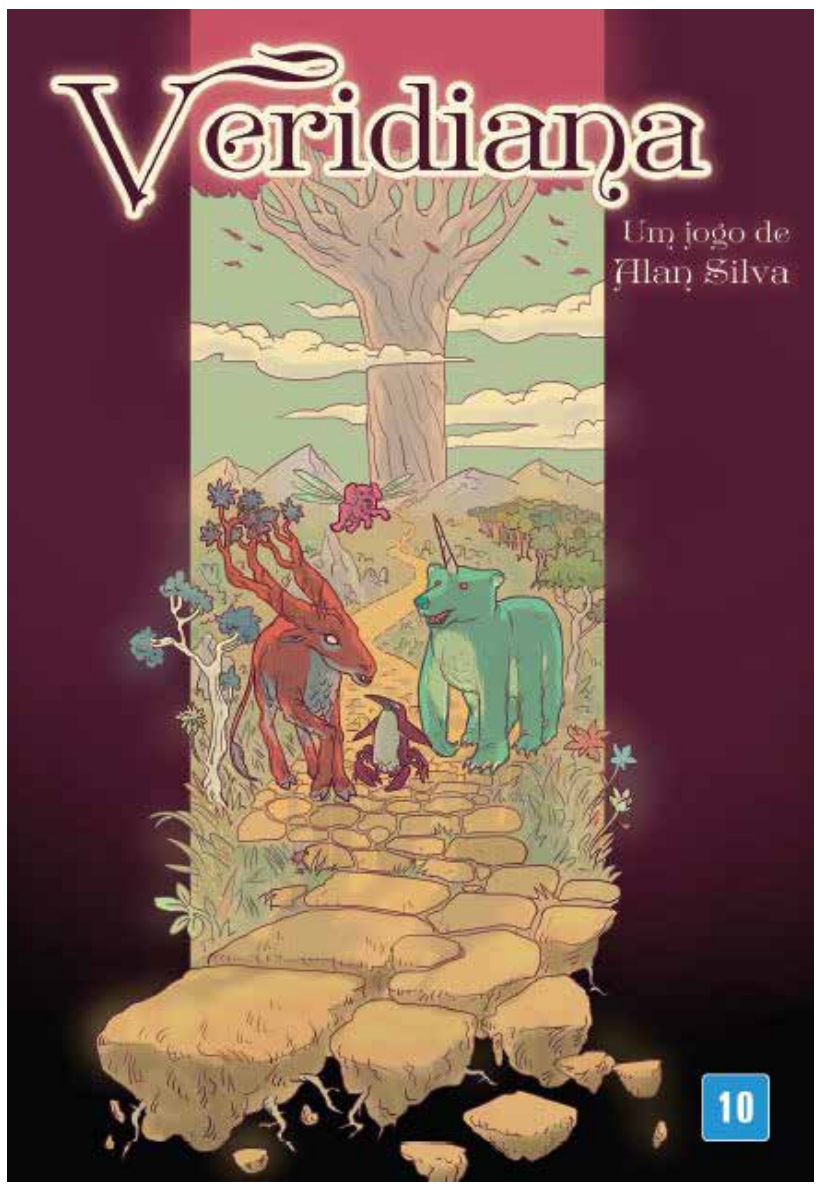

Fonte: Silva (2017). 
Figura 2: Ficha do participante

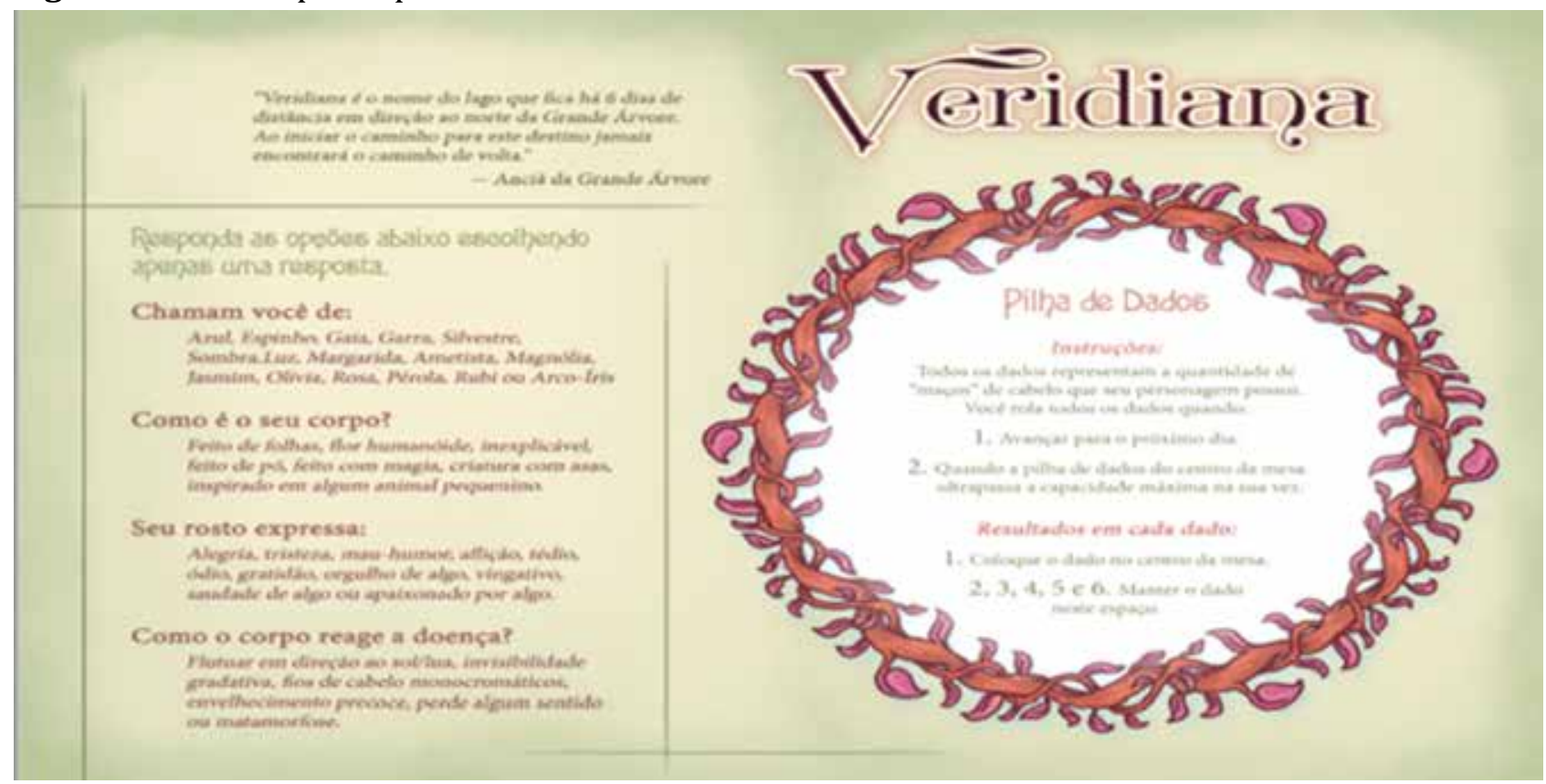

Fonte: Silva (2017).

Figura 3: Ficha de centro de mesa

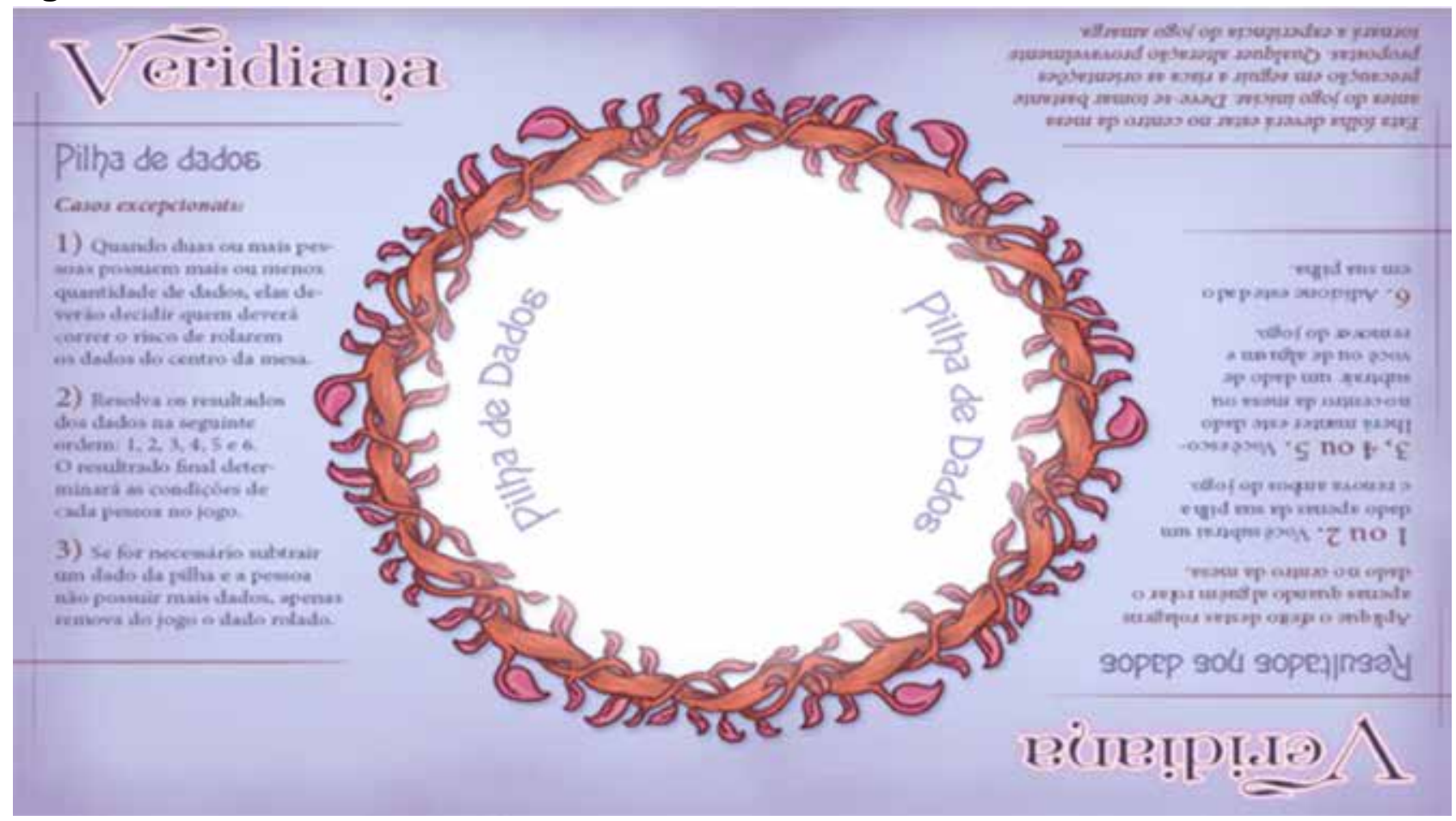

Fonte: Silva (2017).

Em sua narrativa, os jogadores-leitores assumem o papel de personagens do enredo, que são criaturas maravilhosas e com aparências feéricas, que estão exiladas de seu lar, devido a uma enfermidade que faz com que seus cabelos caiam. O problema disso é que, em seus cabelos, está a força vital dessas criaturas. Para salvarem-se, os personagens devem alcançar Veridiana, cidade fictícia do jogo, que fica à beira de um lago mítico, o qual é capaz, segundo a lenda, de curar toda e qualquer doença. Com esse mote, os leitores-jogadores, ao longo da aventura proposta pelo enredo da narrativa do jogo, tomam decisões acerca de sua trajetória, podendo apoiar seus colegas ou 
apressar a chegada individual de seu personagem até Veridiana, salvando-se da enfermidade, porém tirando a oportunidade de os demais permanecerem vivos.

Na Figura 4, vemos que o jogo imerge o participante no enredo de sua narrativa, já

Figura 4: Enredo do jogo-livro Veridiana

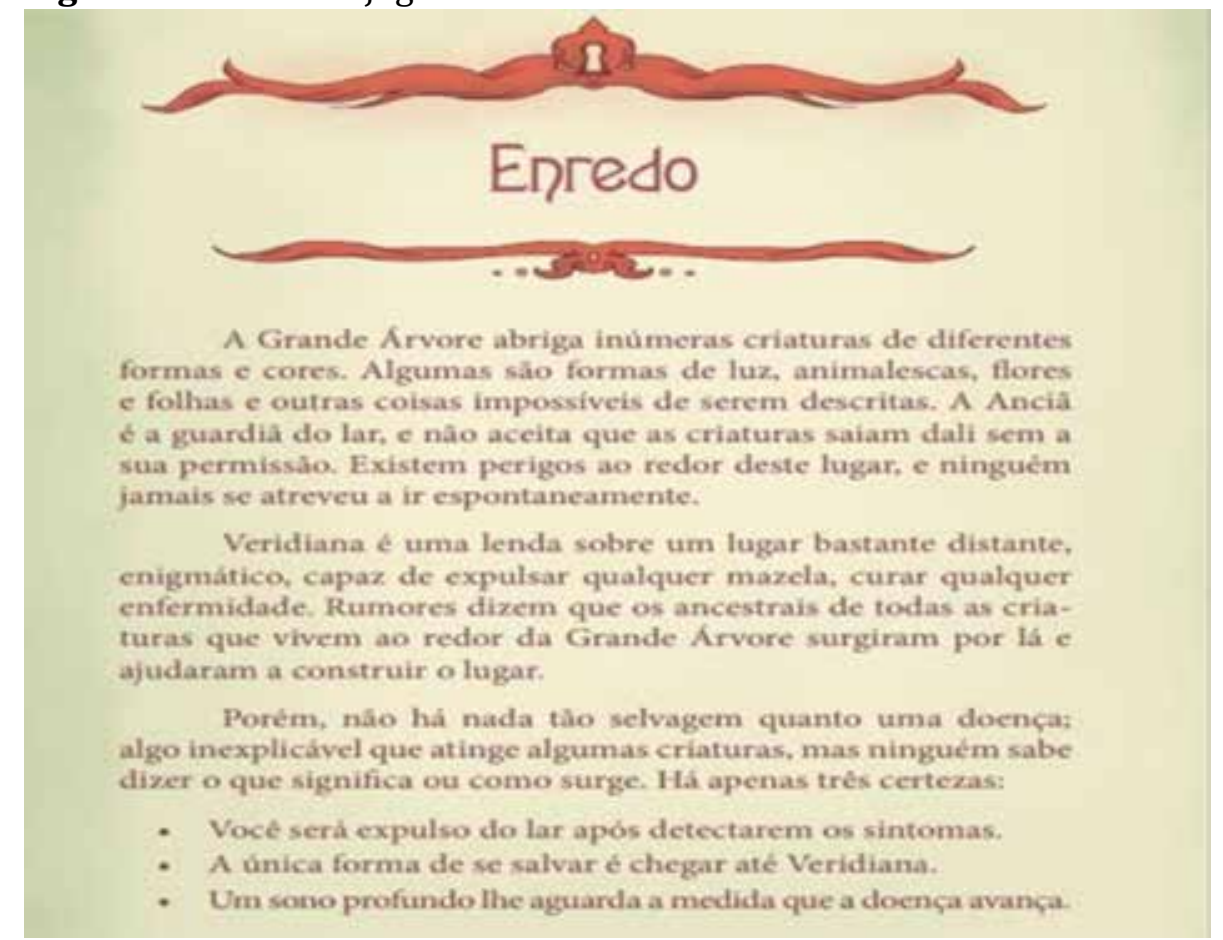

Fonte: Silva (2017).

colocando o conflito com o qual se deparará. Além de decidir sua trajetória, os jogadores-leitores devem comentar como estão se sentindo a partir da tomada de suas decisões. Ao poder tomar decisões acerca de sua trajetória e da de seus colegas e discorrer sobre sentimentos e sensações e como estas interferem na narrativa, é possível uma interessante discussão acerca de decisões éticas para propiciar o bem-estar dos participan- tes do grupo, que, por vezes, fica acima do bem-estar individual. Além disso, essa ação é fundamental porque é ela que faz o jogo acontecer.

O jogo-livro, tal como podemos perceber, apresenta, assim, os elementos de games apresentados por Fardo (2013) e Tolomei (2017), imergindo os jogadores em narrativa, níveis, regras, competição, desafio e recompensa. Podemos ver isso no quadro a seguir.

Quadro 4: Elementos de gamificação e suas descrições no jogo-livro Veridiana

\begin{tabular}{|c|c|}
\hline Elementos & Descrição \\
\hline Narrativa & $\begin{array}{l}\text { O jogo propõe a história de criaturas sobrenaturais que necessitam ir em busca } \\
\text { de um lago, caso não queiram perder sua vida. Somente uma dessas criaturas } \\
\text { conseguirá chegar até lá. }\end{array}$ \\
\hline Níveis & $\begin{array}{l}\text { À medida que a história se desenvolve, os jogadores-leitores, entendidos como } \\
\text { os personagens da narrativa, vão chegando mais próximo do lago mítico, mas } \\
\text { somente um, o ganhador, chegará lá. }\end{array}$ \\
\hline Desafio/Missões & $\begin{array}{l}\text { Os jogadores-leitores têm a missão de chegar até o lago mítico de Veridiana, caso } \\
\text { queiram salvar suas vidas, podendo ajudar seus amigos ou focar apenas em sua } \\
\text { jornada. }\end{array}$ \\
\hline
\end{tabular}




\begin{tabular}{|c|l|}
\hline Regras & $\begin{array}{l}\text { O jogo avisa que, sob pena de serem expulsos do lar, os demais personagens } \\
\text { não podem descobrir os sintomas da doença que acometem os outros. Ainda, } \\
\text { é sabido que só há como se salvar se chegar até Veridiana, caindo em um sono } \\
\text { profundo quanto mais se passa o tempo. Além disso, os jogadores recebem peças } \\
\text { que representam sua quantidade de vida e em cada rodada poderão ganhar mais } \\
\text { peças ou perdê-las, dependendo de quanto o jogador tirou nos dados. }\end{array}$ \\
\hline Feedback & $\begin{array}{l}\text { O feedback acontece em cada jogada, pois, após lançarem os dados e decidirem } \\
\text { a ação que irão tomar no jogo, os personagens comentam como se sentiram em } \\
\text { relação a jogada do companheiro. }\end{array}$ \\
\hline Competição & $\begin{array}{l}\text { Desde o início do jogo, os participantes sabem que somente um deles conseguirá } \\
\text { chegar ao lago mítico de Veridiana, precisando formular estratégias que os } \\
\text { façam, sozinhos, conseguir esse objetivo. }\end{array}$ \\
\hline Engajamento & $\begin{array}{l}\text { Cada jogador-leitor representa um personagem do enredo da narrativa, sendo, } \\
\text { portanto, o participante imergido totalmente na história. }\end{array}$ \\
\hline Recompensa & $\begin{array}{l}\text { Os jogadores são recompensados caso consigam chegar a Veridiana, conseguindo } \\
\text { salvar-se do sono profundo. }\end{array}$ \\
\hline Pontuação/ & $\begin{array}{l}\text { É medida por peças. O jogador começa recebendo quatro dessas peças, e pode } \\
\text { ter placar maior ou menor dependendo da pontuação obtida através do dado. } \\
\text { Quando houver redução de pontos, os personagens também perdem cabelos. }\end{array}$ \\
\hline Progressão & $\begin{array}{l}\text { É um jogo em que os personagens são encorajados a apoiar um aos outros, } \\
\text { portanto não háum ranking propriamente dito, mas, ao passo que os personagens } \\
\text { perdem os cabelos, saem do jogo, o que evidencia um certo ranqueamento a } \\
\text { partir da chegada dos personagens sobressalentes a Veridiana. }\end{array}$ \\
\hline Ranking &
\end{tabular}

Fonte: Elaborado pelo autor.

Além disso, há propriedades de design de games, apresentados por Deterdinget al.(2011), sendo essas características associadas à jogabilidade (gameplay) que identificam esses elementos em variados níveis de abstração e se classificam do mais concreto ao mais abstrato, sendo eles:

Quadro 5: Níveis de elementos de design de games associados à jogabilidade

Nível Descrição

Componente e soluções de design de interação, comuns e bem-sucedidos

Padrão de design de interface de games

Padrões e mecânicas de
design de games

Princípios e heurísticas de design de games, orientações avaliativas para abordar um problema para um problema conhecido em um contexto, incluindo implementações de protótipos.

Parte em geral relacionada à jogabilidade, como as rodadas.
Orientações avaliativas para abordar um problema de design ou analisar uma dada solução de design.

\section{Exemplo em Veridiana}

O uso de fases e do placar que é observado

na obra através dos cabelos dos personagens

Rodadas, recursos limitados dos personagens, limitação de tempo.

Presente no jogo ao definir o objetivo de chegar em Veridiana 


\begin{tabular}{|c|c|c|}
\hline $\begin{array}{c}\text { Modelos conceituais de } \\
\text { unidades de design de games }\end{array}$ & $\begin{array}{c}\text { Modelos conceituais dos componentes fantasia e } \\
\text { dos jogos ou da experiência de jogar } \\
\text { curiosidade presentes } \\
\text { em toda a narrativa } \\
\text { da obra, ao relacionar } \\
\text { elementos mitológicos } \\
\text { com desafios éticos, } \\
\text { permitindo discussões. }\end{array}$ \\
\hline $\begin{array}{c}\text { Modelos e processos de } \\
\text { design de games }\end{array}$ & $\begin{array}{c}\text { Design centrado no } \\
\text { jogador e game design } \\
\text { com consciência de } \\
\text { valores }\end{array}$ \\
\hline
\end{tabular}

Fonte: Adaptado de Deterding et al. (2011 p. 12).

Com isso, o jogo se baseia na leitura compartilhada do manual, que fornece as regras para administração dos dados (o jogo utiliza um total de 25 dados de seis faces) e gerenciamento dos personagens. 0 jogo introduz a história, e os jogadores a continuam. Comporta até 4 pessoas e tem duração média de 45 minutos. 0 jogo se desenrola alternando entre informações do livro-base e detalhes criados pelos personagens para ultrapassarem os desafios, que devem ser criados em conjunto entre os jogadores. Durante a par- tida, a quantidade de dados vai se alterando entre os personagens e, caso algum dos jogadores "perca" todos os seus dados, significa que seu cabelo inteiro caiu, não podendo mais continuar a jornada.

Com base nisso, percebemos que há a possibilidade de desenvolvimento de diferentes estratégias de leitura ao longo do jogo. No quadro a seguir, com base na discussão que empreendemos anteriormente a partir de Cafieiro (2010), apresentamos a análise dessas estratégias.

Quadro 6: Estratégias de leitura a serem desenvolvidas a partir de Veridiana

\begin{tabular}{|c|l|}
\hline Estratégia de leitura & \multicolumn{1}{c|}{ Como ocorre em Veridiana } \\
\hline Fixar objetivos & $\begin{array}{l}\text { Por se tratar de um jogo, é necessário que o jogador-leitor tenha como } \\
\text { objetivo ser o campeão da partida. Para isso, ele precisa se engajar na } \\
\text { leitura da narrativa de Veridiana e se atentar às regras estipuladas } \\
\text { pelo jogo. }\end{array}$ \\
\hline Contextualizar o texto & $\begin{array}{l}\text { É preciso que o estudante perceba o gênero com o qual está } \\
\text { lidando, quais características ele apresenta, bem como entenda seus } \\
\text { elementos ficcionais. }\end{array}$ \\
\hline Mobilizar conhecimentos & $\begin{array}{l}\text { Ao longo da atividade, é necessário que o estudante perceba que está } \\
\text { se inserindo numa situação ficcional e mobilize estratégias para sua } \\
\text { imersão, sendo a principal delas evocar seus conhecimentos prévios } \\
\text { acerca da ficção para realizar suas possíveis jogadas no percurso do jogo. }\end{array}$ \\
\hline Fazer predições & $\begin{array}{l}\text { Ao se engajar na situação de leitura, o leitor sempre realiza predições } \\
\text { do que pode encontrar no texto. No caso de Veridiana, certamente, } \\
\text { ao se deparar com a situação, o estudante perceberá que terá que ser } \\
\text { protagonista de sua leitura. Além disso, ao ler os primeiros motes da } \\
\text { narrativa, certamente, o jogador-leitor construirá hipóteses de como } \\
\text { fazer para chegar ao lago mítico de Veridiana, formulando estratégias } \\
\text { que possam fazê-lo ser o ganhador da partida. }\end{array}$ \\
\hline
\end{tabular}




\begin{tabular}{|c|c|}
\hline Localizar informações & $\begin{array}{l}\text { É preciso que o jogador-leitor saiba que, por se tratar de um jogo, } \\
\text { ele precisará de elementos que compõem a competição, devendo } \\
\text { procurar, no manual, esse material. Além disso, ele necessitará saber } \\
\text { onde encontrar informações que ditam as ações que eles devem } \\
\text { empreender ao longo da competição. }\end{array}$ \\
\hline $\begin{array}{c}\text { Inferir sentido de } \\
\text { palavras e expressões }\end{array}$ & $\begin{array}{l}\text { Ao jogar o estudante deverá construir um acordo acerca das } \\
\text { possibilidades de apreensões e interpretações possíveis dentro do } \\
\text { universo da narrativa, considerando, inclusive, o inverso ficcional e } \\
\text { mítico para desvelar sentidos de palavras e expressões. }\end{array}$ \\
\hline $\begin{array}{l}\text { Identificar opiniões } \\
\text { expressas no texto }\end{array}$ & $\begin{array}{l}\text { O personagem tecerá opiniões e identificará as opiniões do texto } \\
\text { durante a narrativa, pois cada uma de suas jogadas será comentada } \\
\text { pelos personagens. }\end{array}$ \\
\hline $\begin{array}{c}\text { Identificar a finalidade } \\
\text { dos textos }\end{array}$ & $\begin{array}{l}\text { É preciso que o estudante perceba que a finalidade do jogo é fazê-lo se } \\
\text { divertir, mas, no caso de sua utilização como ferramenta pedagógica, } \\
\text { ele deve perceber, ainda, como Veridiana propicia sua aprendizagem } \\
\text { das estratégias de leitura. }\end{array}$ \\
\hline Relacionar imagem e texto & $\begin{array}{l}\text { Conforme o jogo avança, as imagens fornecem subsídios para que o } \\
\text { jogador-leitor perceba em que nível se encontra, fazendo-o inferir } \\
\text { uma série de informações que podem o levar a ler mais rapidamente } \\
\text { as semioses verbais, bem como formular estratégias que o levem a } \\
\text { sair de possíveis crises em que o jogo pode imergi-lo. }\end{array}$ \\
\hline $\begin{array}{l}\text { Identificar a função do } \\
\text { uso de articuladores }\end{array}$ & $\begin{array}{l}\text { Ao longo da narrativa, há o uso de marcadores espaciais e temporais, } \\
\text { que fazem a história se desenvolver e situam o personagem, que, no } \\
\text { caso, também é leitor, no enredo da narrativa. }\end{array}$ \\
\hline $\begin{array}{l}\text { Estabelecer relações entre } \\
\text { partes de um texto de modo a } \\
\text { (re)construir a continuidade } \\
\text { temática }\end{array}$ & $\begin{array}{l}\text { O livro-jogo requer que o estudante desenvolva a narrativa em } \\
\text { conjunto com os colegas, e o desenrolar da história é baseado em } \\
\text { suas experiências. Com isso, na leitura, o estudante relacionará } \\
\text { as informações dadas pelo texto com o que ele está vivenciando e, } \\
\text { com isso, construindo referentes que o façam entender os nexos da } \\
\text { narrativa. }\end{array}$ \\
\hline $\begin{array}{l}\text { Relacionar recursos } \\
\text { expressivos e efeitos de } \\
\text { sentido }\end{array}$ & $\begin{array}{l}\text { O uso de recursos expressivos, ao escolher personagens e apresentar } \\
\text { sentimentos e sensações a cada jornada, possibilita uma leitura } \\
\text { para além dos elementos superficiais do texto e auxilia o leitor na } \\
\text { construção de novos significados. }\end{array}$ \\
\hline $\begin{array}{l}\text { Perceber efeitos de } \\
\text { variação linguística }\end{array}$ & $\begin{array}{l}\text { Os estudantes terão contato com a língua em sua estrutura padrão } \\
\text { através do livro-jogo e poderão também ter contato com a variante } \\
\text { urbana. }\end{array}$ \\
\hline Ler globalmente & $\begin{array}{l}\text { As situações mediadas por jogos, normalmente, em decorrência } \\
\text { de serem uma competição, são mais rápidas, já que, caso o jogador } \\
\text { demore, é possível dar tempo aos seus adversários para que estes } \\
\text { formulem estratégias que os levem a serem campeões. Assim, a } \\
\text { todo instante dessa interação, o jogador-leitor deve se valer de uma } \\
\text { leitura atenta, mas rápida, exigindo, por isso, a capacidade de ele } \\
\text { fazer sínteses globais acerca do que lê. }\end{array}$ \\
\hline
\end{tabular}

Fonte: Elaborado pelo autor. 
Assim, com base nas estratégias metacognitivas sintetizadas por Cafiero (2010), o que se percebe é que Veridiana, por ser um texto real e propiciar um engajamento do participante na situação de interação propiciada pela narrativa do jogo, possibilita a construção dessas habilidades, tendo o jogador-leitor que, a todo instante, se utilizar delas para que possa atingir o objetivo de ser o campeão da competição.

Além disso, como vimos anteriormente, percebendo a dimensão interacional da linguagem, Antunes (2003) formula uma série de implicações pedagógicas que essa percepção tem para o ensino da leitura. Com base nessa formulação, ao adotar Veridiana como uma das ferramentas pedagógicas para o ensino da leitura, está-se trabalhando com um texto autêntico, sem, portanto, ter que se construir uma situação hipotética de interação.

Há, ainda, a dimensão interativa da leitura, no momento em que, além de necessitar se apegar às informações fornecidas pelo texto, o jogador-leitor também ter que interagir com seus adversários, fornecendo as informações necessárias para vencê-los. 0 jogo propicia também uma leitura motiva$\mathrm{da}$, a todo instante propiciada pela vontade de ganhar e de chegar o mais longe possível da competição.

Vale ressaltar que Veridiana não é um Role-Playing Game $(R P G)^{4}$, mas tem um forte elemento narrativo, podendo abarcar diversos temas além da história base que vem no manual, permitindo aos jogadores criar várias outras histórias, o que torna o jogo

4 Role-playing game, também conhecido como RPG, é um tipo de jogo em que os jogadores assumem papéis de personagens e criam narrativas colaborativamente. 0 progresso de um jogo se dá de acordo com um sistema de regras predeterminado, dentro das quais os jogadores podem improvisar livremente. extremamente versátil e uma ferramenta muito útil para introduzir os estudantes à leitura de textos narrativos e construir possibilidades de interpretação.

0 primordial na abordagem do autor em Veridiana é que o livro-jogo pode comportar várias histórias e situações-problema, para além da história apresentada pelo criador do jogo. Destacamos a história virtual -real desenvolvida na fusão da trajetória do jogador e do personagem virtual do game e a possibilidade da criação de personagens com habilidades e capacidades específicas, que, ao criar a história em conjunto com os participantes, serão moldados à realidade da interação, possibilitando discussão de parâmetros críticos e ético-sociais durante a partida.

Dessa maneira, o que se percebe é uma atividade que, mesmo tendo como objetivo principal o desenvolvimento da leitura, permite, também, a interação dos estudantes entre si, respeitando suas vezes de falar, a atuação ética com a vez do outro, o que desenvolve habilidades concernentes à interação oral.

Além disso, caso queira, é possível que o professor utilize a narrativa do jogo para trabalhar questões concernentes à análise linguística/semiótica, tais como o uso de diagramações, cores e a maneira como isso se organiza nas páginas do jogo. Ainda no que se refere ao mesmo eixo, pode-se trabalhar com a utilização de verbos no imperativo ou de verbos modais ao longo da explicitação das regras, bem como o uso de articuladores espaço-temporais ao longo da narrativa.

De igual maneira, é possível analisar as características do gênero, bem como propiciar a escrita dos estudantes, seja na formulação de outros jogos que partam de uma história ficcional seja na construção de outras narrativas escritas com base na fic- 
ção de Veridiana. Percebe-se, assim, que as possibilidades de trabalho com o jogo não se isolam na leitura, mas garantem a possibilidade de construção de habilidades concernentes aos diferentes eixos de aprendizagem da língua, o que, para Rojo (2012), certamente, coloca os estudantes no patamar de analistas críticos dos textos com os quais têm contato. Ora, obviamente, ao longo de suas práticas, os alunos se deparam com jogos, mas, por ainda não ter subsídios de análise crítica, Rojo (2012) entende que seus engajamentos se ancoram em um posicionamento de consumidor acrítico. Cabe à escola, nessa ancoragem, permitir que, através da construção de habilidades de trato com textos reais, os estudantes alcem o patamar de analistas críticos.

\section{Considerações finais}

Neste artigo, tivemos como objetivo norteador analisar o jogo-livro Veridiana, considerando as possibilidades de sua usabilidade na aula de leitura para o ensino básico. Nessa dimensão, ancorou-nos teoricamente as considerações acerca das estratégias de gamificação e as estratégias de leitura que devem ser construídas no ensino básico. Adotamos a perspectiva qualitativa de análise, em sua dimensão documental.

A análise permitiu a compreensão de que Veridiana, por ser um texto que imerge o jogador em uma situação real de interação, à medida que o faz se divertir através da competição, também lhe possibilita a consolidação de estratégias cognitivas e o aprimoramento de estratégias metacognitivas de leitura, tais como a seleção de objetivos de leitura, a análise do contexto de interação, a formulação de predições e inferências, a testagem de hipóteses, entre outras habilidades necessárias à construção de leitores ativos e críticos.
Isso desmonta dois argumentos clássicos dos críticos de games na educação: 1 - o de que um jogo é só uma historinha boba, quando, ao contrário, ele pode suscitar muitas histórias, cujos sentidos se constroem diferentemente para cada sujeito, dependendo da sua bagagem pessoal e de sua história de vida, conjugadas com a maneira como ele interage com o game; e 2 - o de que um game só serve para entreter, já que um jogo, dependendo dos elementos inseridos pelo designer, pode servir aos propósitos educacionais, no tocante à compreensão crítica do mundo e às práticas de linguagem.

\section{Referências}

ALVES, L. R. G., MINHO, M. R. S. E DINIZ, M. V. C. Gamificação: diálogos com a educação. In: Fadel, L. M. et al. (Org.). Gamificação na Educação. São Paulo: Pimenta Cultural, 2014, p. 74-97.

ANTUNES, I. Aula de Português: encontro \& interação. 8. ed. São Paulo: Parábola, 2003.

BRASIL. Ministério da Educação. Base nacional comum curricular. Brasília: MEC, 2018. Disponível em: <http://basenacionalcomum.mec.gov. br>. Acesso em: 19 de agosto de 2018.

CAFIEIRO, D. Letramento e leitura. Formando leitores críticos. In: BRASIL. Ministério da Educação. Língua Portuguesa: Ensino fundamental. Brasília: MEC/SEF. 2010, p. 85-106.

ELKONIN, D. B. Psicologia do jogo. São Paulo: Martins Fontes, 2010.

DETERDING, S.; DIXON, D.; KHALED, R.; NACKLE, L. Gamification: using game design elements in non-gaming contexts. In: Conference on $\mathrm{Hu}-$ man Factors in Computing Systems - ACM, 2011, Vancouver. Proceedings... Vancouver, 2011.

FARDO, Marcelo. A gamificação como método: estudo de elementos dos games aplicados em processos de ensino e aprendizagem. Dissertação (Mestrado) - Universidade Caxias do Sul, Programa de Pós-Graduação em Educação, Caxias do Sul, 2013.

FONSECA, J. J. S. Metodologia da pesquisa científica. Fortaleza: UFC, 2002. 
GEE, J. P. What video games have to teach us about learning and literacy. New York: Macmillan, 2014.

GEE, J. P, Bons videogames e boa aprendizagem. Perspectiva, Florianópolis, v. 27, n. 1, p. 167178, jan./jun. 2009. Disponível em: https:// periodicos.ufsc.br/index.php/perspectiva/article/view/2175795X.2009v27n1p167/14515 . Acesso em: 09 de mai. 2020.

GIL, A. C. Como elaborar projetos de pesquisa. 4. ed. São Paulo: Atlas, 2002.

HUIZINGA, J. Homo Ludens. Paladin: London, 1993.

KENSKI, V. M. Educação e tecnologias: o novo ritmo da informação. Campinas: Editora Papirus, 2012.

KLEIMAN, A. Oficina de leitura: teoria e prática. 5. ed. São Paulo: Pontes, 1997.

KLEIMAN, A. Letramento e suas implicações para o ensino de língua materna. Signo, Santa Cruz do Sul, v. 32, n. 53, p. 1-25, dez. 2007.

KOCH, I. V. G.; ELIAS, V. M. Ler e compreender: os sentidos do texto. 3. ed. São Paulo: Contexto, 2012.

MATTAR, J. Gamificação: Conceito, Críticas e Aplicação a Áreas de Conhecimento. In: RAMOS, D. K.; CRUZ, D. M. (Org.). Jogos digitais em contextos educacionais. São Paulo: CRV, 2018.

MINAYO, M. C. de S. Pesquisa social: teoria, mé- todo e criatividade. Petrópolis: Vozes Limitada, 2011.

ROJO, R. Pedagogia dos Multiletramentos: diversidade cultural e de linguagens na escola. In: ROJO, R.; MOURA, E. (Org.). Multiletramentos na escola. São Paulo: Parábola Editorial, 2012. p. 11-32.

PRENSKY, Marc. Aprendizagem Baseada em Jogos Digitais. Tradução de Eric Yamagute. São Paulo: Senac-SP, 2012.

SILVA, A. Veridiana. 2017. Disponível em: <https://drive.google.com/drive/u/0/folders/0Bzjv8bDBeux4MU5IbDRaTVd5bWs>. Acesso em: 10 mai. 2020.

SILVA, E. T. Concepções de leitura e suas consequências no ensino. Perspectiva, Florianópolis, v. 17, n. 31, p. 11-19, jan./jun. 1999.

SOARES, M. Ler, verbo transitivo. In: PAIVA, A.; PAULINO, G.; MARTINS, A. (org.) Leituras literárias: discursos transitivos. Belo Horizonte: Autêntica, 2008.

TOLOMEI, B. V. A gamificação como estratégia de engajamento e motivação na educação. EaD em Foco, Rio de Janeiro, n. 7, v. 2, p. 145-156, mai./ago. 2017

ORGANIZAÇÃO DAS NAÇÕES UNIDADES PARA A EDUCAÇÃO, A CIÊNCIA E A CULTURA (UNES$\mathrm{CO})$. Relatório de monitoramento global de EPT Educação para Todos 2000-2015: progressos e desafios. UNESCO, 2015.

Recebido em: 16/05/2020 Aceito em: 18/06/2020 